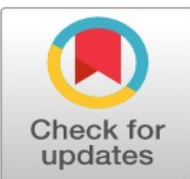

\title{
Transformational leadership climate through learning organization toward the organizational development
}

\author{
Sudarat Pimonratanakan ${ }^{1}$, Tanapat Intawee ${ }^{2 *}$, Kanokporn Krajangsaeng ${ }^{3}$, Santidhorn Pooripakdee ${ }^{4}$ \\ ${ }^{1}$ College of Logistics and Supply chain, Suansunandha Rajabhat University, Bangkok, Thailand \\ 2,4 Faculty of Management Science, Silpakorn University, Bangkok, Thailand \\ ${ }^{3}$ Samitivej Thonburi Hospital, Bangkok, Thailand
}

\section{Keywords \\ Transformational leadership Learning organization Organizational development}

Received: 12 September 2017 Accepted: 22 November 2017 Published: 4 December 2017

\begin{abstract}
The purposes of this research were 1) to study transformational leadership toward the organizational development and 2) to study learning organization toward the organizational development. The sample groups in this research were 400 people for academic personnel and academic support personnel of national universities in Bangkok by using questionnaire as a research tool. The statistics used in data analysis were percentage, mean, standard deviation, and hypothesis testing by using regression analytical statistic. From studying the research result; transformational leadership, learning organization, and overall organizational development were at high level. The hypothesis testing result found that transformational leadership a had positive influence on learning organization and learning organization had a positive influence on organizational development, then the result of this research made us aware of the official relationship of transformational Leadership with learning organization by influencing organizational development. Moreover, this could be a guideline for executives to apply to the operational roles and to define the organization's policy in order to maximize the organizational development efficiency.
\end{abstract}

(c) 2017 The Author(s). Published by TAF Publishing.

\section{INTRODUCTION}

Transformational leadership could change expectation, demands, thoughts, and consciousness of the followers. So transformational leader is able to stimulate followers to focus on the organizational benefit and success over the personal interests (Phuket, 2009; Rijal, 2016) and transformational leadership is necessary for the organizational development because organizational development includes occurring changes of thought, belief, and behavior of the people (El-Ghalayini, 2016; Wittaya-Udom, 2007). Nowadays, organizations including both government and private, have necessity to adapt for survival in swiftly and crucially changing environment. In past decades, organizations all over the world have to engage the changes in politics, economics, and society, especially technology that was changing fast so the organization changes advancement according to the organizational plan as significant for the organization's survival (Lawler \& Worley, 2006). The organization has to be changed and improved constantly. Any organization with no development and improvement would be decayed and shattered as same as normal livings (Intakarn, 2013; Pandla, 2016).

However, transformational leadership is the executive characteristic which could convince personnel to focus on overall vision and goal of the organization as a stimulation for work challenges or enthusiasm, altogether work

\footnotetext{
${ }^{*}$ Corresponding author: Tanapat Intawee

†Email: a_siam103@hotmail.com
} 
achievement, and taking roles in team forming to push forward for the changes by supporting to learn (Sirithanya, 2016; Taiwan, Na-Nan \& Ngudgratoke, 2017). Moreover, leadership contained broad vision to be able to analyze and solve problems, learn and understand self-role which was involved in society, politics, and economic improvements through the good conscious creating for society (Wittayakulvanich, Yongsorn \& Sutakul, 2016) that is involved with high-level learning organization which would have the characteristic of creating wisdom due to self-inspection or self-observation and conducting experiment to know the effect on each choice and adapting the operation guideline to achieve the organizational goal which was the organization's efficiency (Bo Shing \& Xiaodie, 2017; Garvin, Edmondson \& Gino, 2008) throughout the organization which was the learning organization by having concepts and principles that focus on improving human and organization via strategies and learning procedures altogether and thoroughly in organization by using the concept of knowledge management and supporting factors which were the supporting tools to create valuable knowledge and innovation for becoming a quality and skillful organization (Karim, Elyas, Mahmood \& Hossein, 2017, Marquardt, 2003).

The organizational development is one of the methods that develops to help each organization to maintain and grow among the recent environment variations that cause benefit to the organization in both present and future to maintain among occurring changes challenge (Kejranun, 2008) throughout the organizational development that has the purpose to help organizations and their members in many ways, first, by focusing on high goal setting in operation of the organization and achieving the setting goal, second, by maximizing the work efficiency and, third, by organizational development focused on encouraging the organizational members to engage and resolve conflicts creatively and incepting cooperative attitudes to resolve the organizational obstacles together which was the way to merge the personal and organization goals together that could build good relations between each department in the organization including leaders and subordinates at every rank of the organization (Laohanun, 2007: 57; Mahdieh, 2015). From the reasons mentioned above, researchers had an interest in studying about transformational leadership through learning organization toward the organizational development that the result from this research was able to be used as a guideline in planning strategy for learning organizational management that would lead to further efficiency increasing and organizational success.

\section{Research Objectives}

1. To study transformational leadership toward learning organization.

2. To study learning organization toward organizational development.

\section{LITERATURE REVIEW}

To Creating Concept Framework and Research Hypotheses

Researchers had researched the theories throughout collecting documents and related researches to create concept framework as follows.

\section{Transformational Leadership Concept of transformational leadership}

Bass (1985) said that the transformational leadership Theory is the theory about leader who is able to explain the principle of the organizational change management most while Avolio, Bass \& Jung (1999) had proposed the Model of Full Range of Leadership which consisted of 3 leaderships as follows, transformational leadership, Transactional Leadership, and Laissez-faire Leadership. Ferris et al. (2007) and Robbins, Judge \& Campbell (2010) said that leader is a person who can inspire the follower through his work, thought, and acting behavior and there were 2 significant theories in this group which were Power Leadership and transformational leadership.

However, transformational leadership is one of the Models of Full Range of Leadership which consisted of 5 significant concepts as follows (Burns, 1978; Downton, 1973; House, Hanges, Javidan, Dorfman \& Gupta, 2004; Weber, 1947; Zaleznik, 1992). From 5 of the mentioned basic concepts, Bass (1985) brought them to create the theory of Full Leadership by expanding Burn's concept. In Bass' (1985) vision, he said that transformational leader would behave himself as a representative for the change by stimulation, attitude changing, belief changing, and motivation changing of the follower from lower state to the higher state via the stimulation that transformational leader would prepare for the changes by proposing visions, developing emotional relationship with followers, and making followers aware and believe in higher goal than expected which was higher than the personal interest.

On the other side, researchers had defined transformational leadership as a behavior of the leader that stimulated and convinced subordinates to be motivated or desire to work. The leader would have the power for emotionally stimulating employees to follow the leader. From the men- 
tioned concept, it would lead to the hypothesis testing that the hypothesis was as follows.

H1: Transformational leadership had a positive influence on learning organization.

\section{Learning Organization Concept of learning organization}

Marquardt \& Reynolds (1994) in the global learning organization, said that learning organization was the organization which had the atmosphere that affected the learning stimulation of a person or a group to be occurr quickly by using critical thinking procedures to provide understanding of the happening events. The learning method was dynamic by relying on learning, managing, and using knowledge as a tool to achieve success along with using modern technology.

Marquardt (1996) proposed that learning organization could be created by connecting 5 related subsystems by having learning subsystem as the main subsystem while there were other 4 subsystems which were Organization Subsystem, People Subsystem, Knowledge Subsystem, and Technology Subsystem. These 5 subsystems were important and necessary for each other because if any subsystem was missing, it could affect other subsystems.

However, Senge (1990) had proposed in a book, "The Fifth Discipline: The Art and Practice of learning organization", which was the systematic thinking. As a knowledgeable person, improving thinking pattern, team learning, and creating vision together were the knowledge discussion for creating co-learning. Argyris \& Schon $(1978,1996)$ had also proposed the opinion that organization had to learn continuously and constantly transfer knowledge which counted as the Organizational learning and the significant fundamental in developing the concept of learning organization.

On the other side, researchers had defined learning organization as an organization that could learn to create knowledge for increasing capability that caused improvement in running the business by leading to organization's co-goal. From the mentioned concept, it would let to the hypothesis testing that the hypothesis was as follows.

H2: Learning organization had a positive influence on organizational development.

\section{Organizational Development Concept of organizational development}

Worley \& Feyerherm (2003) had defined the meaning of Organizational Development by focusing on giving suggestions of Organizational Development process by setting goal or benefit from the change, learning, or knowledge or skill transferring in the system with clarity or enthusiasm in overall system development which applied and used behavioral knowledge in development and reinforcement planning with structural strategy and the process that led to the efficient organization while Burke \& Schmidt (1971) said that Organizational Development was focusing on creating target culture in the changes.

Beckhard (1969) had defined the meaning of Organizational Development as an attempt of Planned Change that led to consider Organization Wide and managed from the Top to Increase Organizational Effectiveness and Health by using Planned interventions in the Organization's Process using Behavioral Science Knowledge which was focused on Organizational Development Process according to the organizational structure and organization's quality improvement.

On the other side, researchers had defined the meaning of Organizational Development as an organization that prioritized in personnel value and organization's progress by focusing on cooperation and participation of the organization's employees. From the necessity that the organization had the development in economic changes, more competitions, and changing social trends. From the mentioned concept, it would lead to the hypothesis testing that the hypothesis was as follows.

H3: Transformational leadership had positive influence on organizational development.

From related literature review, researchers brought them to create the concept framework and testing hypothesis about transformational leadership factor toward the organizational development.

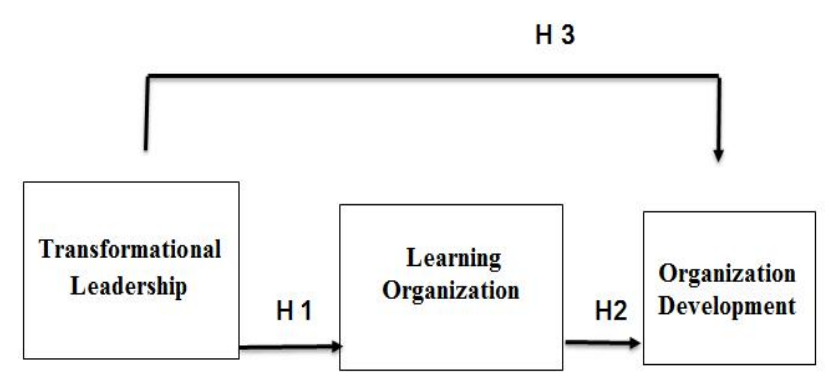

FIGURE 1 . Research concept framework

\section{RESEARCH METHODOLOGY}

\section{Population and Sample Group}

The populations used in this research were academic personnel and academic support personnel of national univer- 
sities in Bangkok consisting of 53,740 people (Office of Higher Education Commission, 2016). The sample groups used in this research were from the random that researchers had specified the sample group size according to the formulas of Yamane (1967) that acquired the sample group for 400 samples and then random the sample by using Quota Sampling according to the population ratio.

\section{Data Collecting Tools}

This research used Questionnaires as a data collecting tool that divided into 5 parts as follows, part 1 was the questionnaire about general information of the sample, part 2 was the questionnaire about transformational leadership, part 3 was the questionnaire about human resource development, part 4 was the questionnaire about learning organization, and part 5 was the questionnaire about Organizational Development. The questionnaire had defined the Rating Scale according to Likert by dividing into 5 levels which were highest, high, moderate, low, and lowest.

Researchers had the quality verification of the tool by these methods as follows.

1. Verify the Content Validity by allowing experts to consider the congruence, research objective-item coverage, vocabulary definition, and linguistic appropriation of the questionnaire by defining Index of Item-Objective Congruence (IOC) at above 0.50 (Pasunon, 2012) and then considering items according to the expert's suggestions and develop the tool properly for further use. The result from IOC test had the value of 0.89 that meant the questionnaire had the validity according to the criteria.

2. Analyzing the tool's reliability by testing the questionnaire before collecting data from a sample group of 50 people and testing the acquired data by finding the value of Cronbach's Alpha according to the Cronbach method (SrisaArd, 2011). From the calculation, it was found that the value of Cronbach's Alpha was 0.9 that meant the questionnaire had the Reliability according to the criteria which had to be greater than 0.7. This has shown that the testing population group had congruence score by the value that is close to 1 meaning that the questionnaire had high reliability.

3. Data analysis that the data analyzing statistic in this research was the Descriptive Statistics which consisted of frequency, percentage, Mean, and Standard Deviation that researchers defined the criteria as follows, score 4.21-5.00 shown the highest level, score 3.41-4.2 shows the high level, score 2.61-3.40 shows the moderate level, score 1.81-2.60 shows the low level, and score 1.00-1.80 shows the lowest level (Srisa-Ard, 2011), and Simple Regression Analysis by using Input method that the abbreviations referred to these meanings as follows;

TL: referred to transformational leadership

LO: referred to learning organization

OD: referred to Organizational Development

\section{RESULTS}

From studying transformational leadership climate through learning organization toward the organizational development as a Quantitative Research was done by using questionnaire as a tool in surveying opinions from the sample group. The sample groups in this research were 400 people from academic personnel and academic support personnel of national universities in Bangkok and analyzing data by using statistical software. Researchers had concluded the research results as follows.

1. Most of the sample group are males 36-40 years old, counted as $38 \%$. Graduated in master's degree or above for $80 \%$, Working experiences at $11-15$ years, counted as $50 \%$ Salary rate at $25,001-35,000$ baht, counted as $52 \%$. And most of them are academic personnel, count as $70 \%$.

2. Overall transformational leadership is at a high level which has $\bar{x}=3.70$, S.D. $=0.72$

3. Overall learning organization is in high level which has $\bar{x}=3.67$, S.D. $=0.73$

4. Overall Organizational Development is at a high level which has $\bar{x}=3.75$, S.D. $=0.71$

\section{Hypothesis Testing Result}

The result has divided the presentation into 2 parts. Part 1 presents the variable attribute test by using relationship testing while Part 2 is the hypothesis testing by using Simple Regression Analysis as shown in Table 1 and Table 2.

TABLE 1. S.D and correlation analysis of transformational leadership towards organizational development factor

\begin{tabular}{lcccc}
\hline \hline Variables & TL & LO & OD & VIF \\
\hline Mean & 3.70 & 3.67 & 3.75 & - \\
$S D$ & 0.72 & 0.73 & 0.71 & - \\
TL & - & & & 2.91 \\
LO & $0.72^{* *}$ & - & & 2.86 \\
OD & $0.75^{* *}$ & $0.76^{* *}$ & - & 2.95 \\
\hline${ }^{* p<0.05,{ }^{* *} p<0.01,{ }^{* * *} p<0.001}$ & &
\end{tabular}

From Table 1 which shows the analysis result, mean, S.D and correlation of studying variables, it was found that 
transformational leadership variable related to learning organization variable was statistically significant at a level of 0.01 , transformational leadership variable had a positive influence on learning organization, learning organization variable related to Organizational Development variable was statistically significant at a level of 0.01 .

Considering Variance Inflation Factors (VIF) value of Response variable, it was found that the values were 2.54-3.45 that were less than 10 (Hair, Black, Babin, Anderson \& Tatham, 2006) which showed that Antecedent variable had no relative problems and was able to analyze the pluralism regression as shown in Table 2 .

TABLE 2. Simple regression analysis

\begin{tabular}{|c|c|c|c|}
\hline \multirow[t]{2}{*}{ Explanatory Variable } & \multicolumn{3}{|c|}{ Hypothesis/Response Variable } \\
\hline & $\begin{array}{c}\text { H1 } \\
\text { (L0) }\end{array}$ & $\begin{array}{c}\text { H2 } \\
\text { (OD) }\end{array}$ & $\begin{array}{c}\text { H3 } \\
\text { (OD) }\end{array}$ \\
\hline TL & $\begin{array}{c}0.650 * * * \\
(0.060)\end{array}$ & - & $\begin{array}{c}0.620^{* * *} \\
(0.065)\end{array}$ \\
\hline LO & - & $\begin{array}{c}0.661^{* * *} \\
(0.062)\end{array}$ & - \\
\hline Adjusted $R^{2}$ & 0.365 & 0.370 & 0.369 \\
\hline
\end{tabular}

From Table 2, which was the Simple Regression analysis result for hypothesis testing could be explain as follows.

1. Transformational leadership had a positive influence on learning organization significantly at a level of 0.001 ( $\beta=$ $0.650, p<0.001$ ) from the results according to the hypothesis 1.

2. Learning organization had a positive influence on Organizational Development significantly at a level of $0.001(\beta=$ $0.661, p<0.001$ ) from the result according to the hypothesis 2 .

3. Transformational leadership had a positive influence on Organizational Development significantly at a level of 0.001 ( $\beta=0.620, p<0.001)$ from the result according to the hypothesis 3 .

\section{DISCUSSION}

From the research result of transformational leadership climate through learning organization toward the organizational development, it could be discussed as follows.

Transformational leadership had an overall opinion at a high level because the transformational leadership in the organization was the change in most of the minor components that the sample group were able to acknowledge the transformational leadership at a high level which had an issue in Inspirational Motivation that was at a high level while everyone had participated in the work according to the inspiration by the leader to achieve the tasks.

Learning organization had an overall opinion at a high level because the learning organization in each organization, has a sample group aware of shared vision at a high level. It allows using vision definition or the organization's improvement direction participation procedure by allowing colleagues or related persons to participate in vision definition or the organization's improvement direction to clarify and modernize the vision which conformed to the 5 fundamental principles of Senge (1990) which were Systematic Thinking, Personal Mastery, Improving Mental Models, team learning, and Building Shared Vision.

Organizational Development had an overall opinion at a high level because, the Organizational Development, sample group was aware of focusing on participation and cooperation of the organization's employees and the necessity that the organization had to develop for supporting the changing social trends including economic changes and more competitions. From the testing result, it was found that transformational leadership through learning organization towards Organizational Development, the study result had accepted the hypotheses.

\section{Hypothesis 1}

Transformational leadership had a positive influence on learning organization that may be because of the transformational leadership that had an influence on learning organization in terms of shared vision which was the activity that used vision definition or the organization's improvement direction participation procedure and focused on flexible management to support the changes that could happen anytime. Then the organizational operations became more work groups or team working that caused learning and development in a learning organization which conformed to the concept of Senge's study (1990) that said "the important role of learning organization leader was the planning that was the responsibility for achieving operation that caused learning and taking responsibility of the organizational structure, policy, strategy, and operation by performing as a leader, instructor, and co-working with the members due to the recent society which was the changing society for learning".

\section{Hypothesis 2}

Learning organization had a positive influence on Organizational Development that may be because of the learn- 
ing organization that had an influence on Organizational Development in terms of being the learning organizationthat showed the Organizational Development by substantial performance and improved the organization to become high-level learning organization by allowing organization's executives to study activities in each organization that were top-level learning organization for sharing knowledge and applying the guideline in improving organization to become the learning organization. Then the result was the organization's personnel would effectively work with 4 types of effectiveness that conformed to the concept of Drucker (2007) that said " to manage the quality of an organization, it is necessary to provide a learning system to encourage personnel learning at every rank continuously and constantly that theere is encouragement from the organization to learn and share knowledge inside the organization including the organization's personnel who properly apply the knowledge in each situation and also resolve and decide organization's issues well".

\section{Hypothesis 3}

Transformational leadership had a positive influence on Organizational Development that may be because of the transformational leadership that had an influence on Organizational Development due to the organization's goal that must prepare the new operation personnel to ensure the organization that they got skilled personnel suited for further changing tasks which conformed to the concept of Robbins et al. (2010) that said " when the leader attempts to stimulate the follower to focus on the organization's benefit over personal interests, the leader would be aware of the demand of self-development of the follower, changing perception or awareness of the follower toward the regular problems with a new perspective including the leader attempting to stimulate and convince followers to attempt for the organization's achievement".

\section{Research Benefits}

\section{Management benefit}

From the study of transformational leadership through learning organization toward Organizational Development, it was found that transformational leadership would cause the Organizational Development for the learning Organization.

From the study mentioned above, it was found that the 2 major factors which were transformational leadership and learning organization both had the positive influence on high-level Organizational Development. So if there were any organizations requiring to improve their organizations, they were necessary to prioritize in improving executives at every rank in the organizations, which recently found that they were still at a moderate-level, to reach a higher level in term of transformational leadership by ideologically improving leaders and their power which should focus on creating values for executives at every rank to prioritize on behaving themselves as good models by defining policies to encourage the good models in the organization or held activities that allowed executives to participate with employees at every rank that would make the employees get closer and notice the good model from executives that the executives and employees would have an opportunity to do the activities together.

For the Organizational Development, the organization should have the guideline for the organizational development especially the acknowledgement that the leader supports the changes while executives should provide the communication channel between leader and followers about the Organizational Development and support the executives to spend time to give an advice to employees about Organizational Development, rewards or incentives when employees could successfully perform changing or improving the organization as planned that the organization should define policies to support the Organizational Development from bottom to the top that would cause employees to acknowledge and participate in the Organizational Development.

\section{Theoretical benefit}

This research would cause theoretical benefits as follows, concepts and theories integration about transformational leadership of Avolio et al. (1994) and concept about learning organization of Senge (1990) to apply by considering the learning organization as the Mediator and studying a result factor which was the Organizational Development by studying in terms of Casual Research to prove the influence between transformational leadership variable and Organizational Development which was focuing on testing the middle variable or Mediator of the learning organization including study in context of academic personnel and academic support personnel that still had few researches that focused on studying learning organization toward organization as the middle variable or Mediator due to most of the past researches that would study learning organization as the Antecedent Variable and study transformational leadership as the Response Variable. Besides, the research result found that the learning organization which is defined as the Mediator had an influence on transferring transformational 
leadership toward the Organizational Development and the mentioned discovery could academically be topped up to study the influence of this variable on another variables.

\section{SUGGESTIONS FOR FURTHER RESEARCH}

For the suggestions for further research, it should be performed as follows.

1. There should be studies by using the concept framework to study the organization in different contexts for further Organizational Development.
2. There should be another theory applied in creating variable that is various and proper to study target context of the study by using learning theory creating research variables. 3. For the learning organization and the Organizational Development, there should be a study for the pattern that is appropriate for the situation in organization due to the operation and organizational culture is different according to the occurring problems in each organization and personal requirements.

\section{REFERENCES}

Argyris, C., \& Schon, D.A. 1978. Organizational learning: A theory of action approach. Reading, MA: Addision Wesley. Argyris, C., \& Schon, D.A. 1996. Organiational learning II. Reading, MA: Addison Wesley.

Avolio, B.J., Bass, B.M., \& Jung, D.I. 1999. Re-examining the components of transformational and transactional leadership using the multifactor leadership. Journal of Occupational and Organizational Psychology, 72(4): 441-462.

DOI: $10.1348 / 096317999166789$

Bass, B.M, 1985. Leadership and performance. New York, NY: Free Press.

Beckhard, R. 1969. Organization development: Strategies and models. Boston, MA: Addison Wesley Publishing Company. Bo Shing, L.A., \& Xiaodie P. J. 2017. Exploring the relationship between leadership, organizational culture, trust, and effec- tiveness of knowledge sharing by forced learning. Journal of Administrative and Business Studies, 3(2): 89-104.

DOI: 10.20474 /jabs-3.2.4

Burke, W.W., \& Schmidt, W.H. 1971. Primary target for change: The manager or the organization? In H.A. Hornstein, B.B.

Bunker, W.W. Burke, M. Gindes \& R.J. Lewicki (Eds.), Social intervention: A behavioral science approach. New York, NY: Free Press.

Burns, J.M. 1978. Leadership. New York, NY: Harper \& Row.

Downton, J.V. 1973. Rebel leadership: Commitment and charisma in the revolutionary process. New York, NY: Free Press.

Drucker, P.F. 2007. Management challenges for the $21^{\text {st }}$ century. New York, NY: Harper Business. El-Ghalayini, Y. 2016. The effects of high performance work system on employee attitudes: A study of international organition. Journal of Administrative and Business Studies, 2(5): 248-263. DOI: 10.20474/jabs-2.5.5

Ferris, G.R., Perrewé, P.L., Ranft, A.L., Zinko, R., Stoner, J.S., Brouer, R.L., \& Laird, M.D. 2007. Human resources reputation and effectiveness. Human Resource Management Review, 17(2): 117-130. D0I: 10.1016/j.hrmr.2007.03.003

Garvin, D.A., Edmondson, A.C., \& Gino, F. 2008. Is yours a learning organization? Harvard Business Review, 86(3): 109-115. Hair, J.F., Black, W.C., Babin, B.J., Anderson, R.E., \& Tatham, R.L. 2006. Multivariate data analysis. New Jersy, NJ: Pearson Prentice Hall Upper Saddle River.

House, R.J., Hanges, P.J., Javidan, M., Dorfman, P. W., \& Gupta, V. 2004. Leadership, culture, and organizations: The globe study of 62 societies. Thousand Oaks, CA: Sage Publications.

Intakarn, N. 2013. The quality of work life of employees affects the potential for organizational development of inter food company limited. Veridian E-Journal The Humanities, Social Sciences and Science, 6(3): 380-394.

Karim Mh, Elyas, K.M., Mahmood, S.N., \& Hossein, A. 2017. Evaluation of human resources re-engineering and knowledge management processes on the economy of Sirjan free trade zone (Iran). International Journal of Business and Eco- $\quad$ nomic Affairs, 2(2): 127-134. DOI: 10.24088/ijbea-2017-22006

Kejranun, N. 2008. Organization behavior. Bangkok, Thiland: Se-Education. Laohanun, S. 2007. Organization development. Bangkok, Thiland: Bansomdejchaopraya Rajabhat University Publisher. Lawler, E.E., \& Worley, C.G. 2006. Designing organizations that are built to change. MIT Sloan Management Review, 48(1): 19-23.

Mahdieh, 0. 2015. Interaction between communication and organizational conflict and its relationship with performance.

International Journal of Business and Administrative Studies, 1(2): 54-60. D0I: 10.20469/ijbas.10002-2 
Marquardt, M.J. 1996. Building the learning organization: A systems approach to quantum improvement and global success. New York, NY: McGraw-Hill Companies.

Marquardt, M.J. 2003. Developing global leaders via action learning programs: A case study at Boeing. Thai Journal of Public Administration, 1(3): 1-25.

Marquardt, M.J., \& Reynolds, A. 1994. The global learning organization. Huntersville, NC: Irwin Professional.

Office of Higher Education Commission. 2016. Personnel statistical data. URL: goo.gl/YtmEmz. Last accessed on 2 July 2017.

Pandla, K. 2016. Drivers and characteristics of high performing organizations. International Journal of Business and Ad- ministrative Studies, 2(3): 57-61. D0I: 10.20469/ijbas.2.10001-3

Pasunon, P. 2012. Market research. Bangkok, Thiland: Silpakorn University Publisher.

Phuket, P. R.N. 2009. Organization and management. Bangkok, Thiland: Think Beyond Books.

Rijal, S. 2016. The influence of transformational leadership and organizational culture on learning organization: A compara- tive analysis of the IT sector Thailand. Journal of Administrative and Business Studies, 2(3): 121-129.

DOI: $10.20474 /$ jabs-2.3.3

Robbins, S.P., Judge, T., \& Campbell, T. T. 2010. Organizational behaviour. Englewood Cliffs, NJ: Financial Times Prentice Hall.

Senge, P. , 1990. The fifth discipline: The art and science of the learning organization. New Yo rk, NY: Currency Double- $\quad$ day.

Sirithanya, K.M.C. 2016. Transformational executives toward the major effectiveness of the teacher in the school under the secondary educational eervice area office 2. Veridian E-Journal the Humanities, Social Sciences and Science, 9(2): 1510-1525.

Srisa-Ard, B. 2011. Fundamental research. Bangkok, Thiland: Suriwayasarn.

Taiwan, A., Na-Nan, K., \& Ngudgratoke, S. 2017. Relationship among personality, transformational leadership, percerived organizational support, expatriate adjustment, and expatriate performance. International Journal of Business and

Ad- ministrative Studies, 3(4): 129-141. DOI: 10.20469/ijbas.3.10001-4

Weber, M. 1947. The theory of economic and social organization. New York, NY: Oxford University Press.

Wittayakulvanich, V., Yongsorn, J., \& Sutakul J. 2016. Analytical elements of effective leadership for students of faculty of engineering Kasetsart university. Veridian E-Journal The Humanities, Social Sciences and Science, 9(3): 65-82.

Wittaya-Udom, W. 2007. Organization development. Bangkok, Thiland: Ta natuch Printing Company Limited.

Worley, C.G., \& Feyerherm, A.E. 2003. Reflections on the future of organization development. The Journal of Applied

Be- havioral Science, 39(1): 97-115. DOI: 10.1177/0021886303039001005

Yamane, T. 1967. Statistics: An introductory analysis. New York, NY: Harper \& Row.

Zaleznik, A. 1992. Managers and leaders: Are they different? Harvard Business Review, 70(2): 126-135.

— This article does not have any appendix. - 